\title{
An AMPK paradox in pulmonary arterial hypertension
}

\author{
Miranda Sun, Guofei Zhou* \\ Department of Pediatrics, University of Illinois at Chicago, Chicago, USA \\ Email: " guofei@uic.edu
}

Received 27 September 2013; revised 29 October 2013; accepted 8 November 2013

Copyright (C) 2013 Miranda Sun, Guofei Zhou. This is an open access article distributed under the Creative Commons Attribution License, which permits unrestricted use, distribution, and reproduction in any medium, provided the original work is properly cited.

\begin{abstract}
Adenosine monophosphate-activated protein kinase (AMPK) is a heterotrimeric serine-threonine kinase important as a metabolic sensor for intracellular ATP levels and plays a key role in regulating cell survival and proliferation, particularly when cells are exposed to hypoxia. AMPK is critical for lung function, and abnormal AMPK signaling participates in many lung diseases. Recent studies suggest that both inhibition and activation of AMPK are preventive for the development of pulmonary arterial hypertension (PAH). However, the molecular mechanisms by which inhibition or activation of AMPK affects pulmonary hypertension (PH) appear to be distinct. Inhibition of AMPK by compound $C$ blocks hypoxia-induced autophagy and induces apoptosis in pulmonary artery smooth muscle cells, leading to prevention of PAH; activation of AMPK by metformin attenuates the $\mathrm{PH}$ phenotype induced by hypoxia by regulating endothelial cell function. These seemingly opposing data on the function of AMPK in PH can be partly explained by off-target and compartment-specific effects of AMPK inhibitors and activators and the differentiated expression of AMPK in various cell types and subcellular locations. To elucidate the specific roles of AMPK in the pathogenesis of PAH, it is important to study the role of $A M P K$ in a tissue specific manner combining genetic and biochemical approaches.
\end{abstract}

Keywords: AMPK; Pulmonary Hypertension; Pulmonary Artery Smooth Muscle Cells; Endothelial Cells

\section{INTRODUCTION}

Pulmonary arterial hypertension (PAH) is a disease characterized by increased pulmonary arterial pressure that leads to right ventricular failure, and ultimately, death

${ }^{*}$ Corresponding author.
$[1,2]$. Active vasoconstriction as well as vascular remodeling leads to manifestation of the disease. Pulmonary artery remodeling includes survival and proliferation of pulmonary artery smooth muscle cells (PASMC), which cause the development and progression of high pulmonary vascular tone observed in PAH patients [3]. Hypoxia-induced pulmonary hypertension $(\mathrm{PH})$ in several animal models is a well-established and commonly employed method to investigate the pathogenesis of PAH. Hypoxia is known to induce right ventricular hypertrophy (expressed as a ratio of right ventricular weight to left ventricular plus ventricular septum weight, $\mathrm{RV} /(\mathrm{LV}+$ $\mathrm{S}$ ), increased pulmonary arterial pressure, and pulmonary arterial wall remodeling [4]. Although major advancements have been made in the last two decades in the understanding of the development and treatment of $\mathrm{PAH}$, the exact mechanisms in the pathogenesis are still not clear and there is currently no cure for this disease.

Adenosine monophosphate-activated protein kinase (AMPK) is a heterotrimeric serine-threonine kinase important as a metabolic sensor for intracellular ATP levels [5]. AMPK is composed of three subunits, the catalytic $\alpha$ subunit and the regulatory $\beta$ and $\gamma$ subunits. Each of the subunits can be found in multiple isoforms $(\alpha 1, \alpha 2, \beta 1$, $\beta 2, \gamma 1, \gamma 2, \gamma 3)$, giving a total of 12 combinations having different tissue distribution and subcellular localization patterns [5,6]. AMPK is allosterically activated by the binding of two AMP molecules to the $\gamma$ subunit, allowing the phosphorylation of $\alpha \mathrm{Thr} 172$ in the catalytic domain via an upstream kinase, thus increasing kinase activity, and inhibiting AMPK dephosphorylation [5]. AMPK is sensitive to stress and low energy states when the AMP/ATP ratio increases, such as in hypoxia. AMPK is also considered a "master switch" in regulating cell survival and proliferation. For example, AMPK activity is increased in rapidly proliferating cells like cardiac fibroblasts and cancer cells $[7,8]$. In addition, cell cycle regulation, decision to enter autophagy, apoptosis, and other cell fate decisions are regulated by AMPK (Figure 1) $[9]$. 


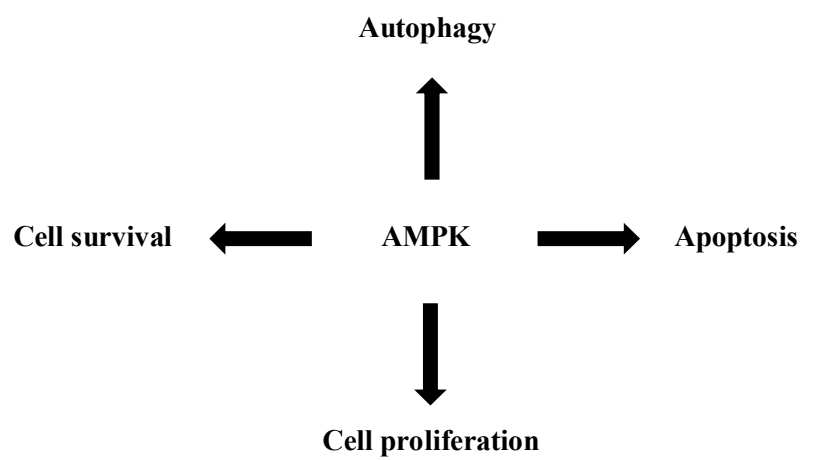

Figure 1. Schematic diagram of the roles of AMPK in the cellular response to hypoxia.

In the lung, both isoforms of the catalytic $\alpha$ subunit are expressed $[5,10,11]$. Accumulating evidence suggests that AMPK is critical for lung function, and abnormal AMPK signaling participates in lung disease [10,12-16]. For example, in alveolar epithelial cells, AMPK is critical for the regulation of sodium transport $[12,13,16]$. Recent reports also suggest that acute or moderate hypoxia can activate AMPK through $\mathrm{Ca}^{2+}$ /calmodulin-dependent protein kinase kinase- $\beta$ (CaMKK $\beta)$ independent of the AMP/ATP ratio [13-15]. In pulmonary endothelial cells, AMPK promotes endothelial barrier function [10]. PASMC express both $\alpha$ isoforms, of which the $\alpha 1$ isoform contributes up to $80 \%$ of the total AMPK activity [5]. However, the role of AMPK in lung, particularly in PAH, appears to be inconclusive: We have shown that AMPK inhibition is beneficial for the treatment of PH [17] whereas others suggest that AMPK activators such as metformin and AICAR are protective against experimental PH [18]

(http://licensing.inserm.fr/fiche.php?artid=179). In this review, we will present an overview on the current literature on the role of AMPK in PAH, analyze the causes of discrepancy, and discuss the future directions to elucidate the role of AMPK in the lung.

\section{INHIBITION OF AMPK PREVENTS AND REVERSES HYPOXIA-INDUCED PH}

Recently, we have demonstrated the physiological significance of AMPK in PAH [17]. In human pulmonary artery smooth muscle cells (HPASMC) isolated from PAH patients, levels of AMPK phosphorylated at $\alpha \mathrm{Thr}$ 172 (pAMPK) are elevated compared to normal HPASMC while total AMPK levels remained the same. In a hypoxia-induced PH mouse model, pAMPK in the lung tissue of mice exposed to hypoxia for three weeks is also increased, and elevation of pAMPK occurs in mouse PASMC. These results suggest that AMPK is hyperphosphorylated in PASMC of PAH.

We also report that AMPK is necessary for PASMC survival in hypoxia [17]. HPASMC treated with compound $\mathrm{C}$, an AMPK inhibitor, exhibit decreased viability in hypoxia compared to untreated HPASMC, while inhibition of AMPK in normoxia using compound $\mathrm{C}$ has no effect on viability. As PASMC express both $\alpha 1$ and $\alpha 2$ isoforms of AMPK, the two different isoforms of the catalytic subunit are found to regulate separate functions that prevent cell death in hypoxia. Specifically, AMPK $\alpha$ 2 promotes HPASMC survival by increasing expression of pro-survival proteins such as MCL-1. On the other hand, AMPK $\alpha 1$ functions through regulating autophagy. The inhibition of AMPK $\alpha 1$ prevents autophagy and, thus, causes cell death independent of apoptosis (Figure 2).

Furthermore, using an in vivo mouse model, we show that inhibition of AMPK by compound $\mathrm{C}$ is able to prevent the development of hypoxia-induced $\mathrm{PH}$ when compound $\mathrm{C}$ is administered before a three-week hypoxia exposure. When mice are treated with compound $\mathrm{C}$ prior to hypoxia exposure, they have significantly reduced $\mathrm{RV} /(\mathrm{LV}+\mathrm{S})$ ratio, right ventricular systolic pressure (RVSP), and vascular remodeling (arterial wall thickness). Compound $\mathrm{C}$ can also partially reverse hypoxia-induced $\mathrm{PH}$ when it is administered after the onset of hypertension. In this model, mice are exposed to hypoxia for two weeks to induce hypertension and are then treated with compound $\mathrm{C} . \mathrm{RV} /(\mathrm{LV}+\mathrm{S})$ ratio and vessel wall thickness are significantly reduced, but RVSP was not affected. In both models, a marker of hypoxia, HCT, is unaffected by compound $\mathrm{C}$ treatment, suggesting that it is unlikely that compound $\mathrm{C}$ affects hypoxia-induced PH though an off-target effect on HIF. These results indicate that an inhibitor of AMPK may be a novel therapeutic approach for the treatment of PAH.

\section{ACTIVATION OF AMPK PLAYS A PROTECTIVE ROLE AGAINST PH}

Metformin, a commonly used drug for treating type 2 diabetes mellitus, has recently been shown to treat $\mathrm{PH}$ in animal models. Metformin improves hyperglycemia by increasing peripheral sensitivity to insulin, reducing gas-

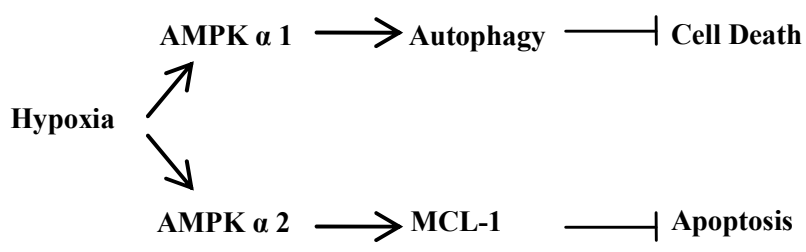

Figure 2. The mechanism by which activation of APMK promotes PASMC survival during hypoxia. Activation of AMPK $\alpha$ 1 and $\alpha 2$ during hypoxia plays a differentiated role in the survival of PASMC: Activation of AMPK $\alpha_{1}$ induces hypoxiainduced autophagy, preventing PASMC death; activation of AMPK $\alpha_{2}$ maintains the expression levels of MCL-1 during hypoxia, preventing cell apoptosis. 
trointestinal absorption of glucose, and inhibiting glucose production by the liver [19,20]. In addition, metformin has been shown to improve cardiovascular function [21]. Studies have demonstrated that metformin carries out a large part of these functions through activation of AMPK [18,22].

Agard et al. have demonstrated that metformin exhibits a protective effect against hypoxia-induced $\mathrm{PH}$ in a rat model [18]. Rats exposed to hypoxia while being treated with metformin showed near normal levels of pulmonary arterial pressure, RV wall thickness, and $\mathrm{RV} /(\mathrm{LV}+\mathrm{S})$ ratio, with the effect being dependent on drug dose. In addition, metformin treatment significantly reduced pulmonary artery remodeling in the lungs of hypoxic rats. As expected, there was an increase in the phosphorylation of acetyl CoA carboxylase, a direct target of AMPK, in the pulmonary arteries of metformin-treated hypoxic rats, demonstrating an increase in AMPK activity. This study also demonstrates attenuation of hypoxic pulmonary vasoconstriction due to improved endothelial function and decreased RhoA/Rho kinase activity after treatment with metformin, which is in agreement with previous studies on metformin and vascular tone [22-24]. Furthermore, treatment with metformin on cultured rat PASMC inhibited proliferation. Consistently, AICAR, another AMPK activator, has also been shown to be protective against experimental $\mathrm{PH}$ [18]

(http://licensing.inserm.fr/fiche.php?artid=179). Thus, these studies suggest that an AMPK activator may be used as therapeutic agent for the treatment of PAH.

\section{DISCUSSION}

In this review, we have discussed seemingly opposing data on the function of AMPK in PAH and hypoxia models of PH. On the one hand, we have suggested that inhibition of AMPK activity prevents and reverses hypoxiainduced PH by inducing PASMC death; on the other hand, Agard et al. have suggested that activation of AMPK protects against hypoxia-induced $\mathrm{PH}$, presumably by regulating endothelial cell function [18]. However, these results need to be viewed with caution due to nonspecific effects of these drugs. This inconsistency can therefore be explained partly by off-target and compartment-specific effects of AMPK inhibitors and activators [25-27] and partly by the differentiated expression of AMPK in various cell types and subcellular locations $[5,10,28]$.

Indeed, the role of AMPK in cell survival, for example, appears to be cell-specific. Some studies show that AMPK is activated in rapidly proliferating cells $[7,8]$ and that inhibition of AMPK induces growth arrest and reduces viability [8,29]. Others report that activation of AMPK inhibits growth and/or survival of cells, particu- larly in systemic vascular smooth muscle cells [30-32]. Our study demonstrates that AMPK $\alpha 1$ plays a role in regulating autophagy while AMPK $\alpha 2$ upregulates the pro-survival protein MCL-1, inhibiting apoptosis. Both isoforms are necessary for PASMC survival in hypoxia; however, suppression of either or both isoforms does not induce cell death under normoxic conditions. Krymskaya and colleagues show that hypoxic activation of AMPK does not contribute to hypoxia-induced proliferation of PASMC [33], supporting our finding that the role of AMPK in hypoxia-induced $\mathrm{PH}$ is mediated by its regulation of PASMC survival. In addition, AMPK is known to be required for hypoxia-mediated vasoconstriction [5,34, 35], a feature of PAH. Thus, these studies suggest that activation of AMPK contributes to the pathogenesis of PAH.

In the study by Agard et al., however, indirect AMPK activation by the drug metformin seems to attenuate, and almost eliminate, PAH phenotype induced by hypoxia. An increase in the phosphorylation of endothelial NOS (eNOS) as a marker of endothelial function and a decrease in phosphorylated MYPT as a marker of RhoA/ Rho kinase activity were observed. Improvement in endothelial function is likely mediated by AMPK activity as several previous studies have shown AMPK activity to lead directly to phosphorylation of eNOS $[22,24]$. It is worth pointing out that the inhibition of PASMC proliferation with metformin treatment is possibly due only in part to AMPK activity. Previous studies on metformin's inhibitory effects on cancer cell proliferation were shown to be only partly dependent upon AMPK [36,37]. Therefore, the protective effects of metformin from hypoxiainduced PH may not be completely attributed to increased AMPK activity.

In conclusion, recent studies have shown what seems like opposite functions for AMPK in PAH. However, in reconciliation, the molecular pathways and the type of cells in which AMPK functions are different. In one set of studies, inhibition of AMPK leads to elevated PASMC cell death, thus preventing $\mathrm{PH}$; in another set of studies, AMPK activation increases eNOS function to attenuate $\mathrm{PH}$. Given the fact that these studies are carried out with chemical AMPK inhibitors and activators, these results need to be interpreted with caution as long-term success in the treatment of PAH with these agents being uncertain due to their non-specific effects [27]. Thus, to elucidate the specific roles of AMPK in pathogenesis of $\mathrm{PAH}$, it is important to study the role of AMPK in a tissue-specific manner combining genetic and biochemical approaches.

\section{ACKNOWLEDGEMENTS}

This study was supported in part by a Pulmonary Hypertension Asso- 
ciation/Pfizer Proof-of-Concept award (G. Zhou) in which American Thoracic Society provides administrative support.

\section{REFERENCES}

[1] Humbert, M., Sitbon, O. and Simonneau, G. (2004) Treatment of pulmonary arterial hypertension. New England Journal of Medicine, 351, 1425-1436. http://dx.doi.org/10.1056/NEJMra040291

[2] McLaughlin, V.V., Archer, S.L., Badesch, D.B., Barst, R.J., Farber, H.W., Lindner, J.R., et al. (2009) ACCF/ AHA 2009 expert consensus document on pulmonary hypertension: A report of the American College of Cardiology Foundation Task Force on Expert Consensus Documents and the American Heart Association: Developed in collaboration with the American College of Chest Physicians, American Thoracic Society, Inc., and the Pulmonary Hypertension Association. Circulation, 119, 2250-2294.

http://dx.doi.org/10.1161/CIRCULATIONAHA.109.1922 30

[3] Durmowicz, A.G. and Stenmark, K.R. (1999) Mechanisms of structural remodeling in chronic pulmonary hypertension. Pediatrics in Review/American Academy of Pediatrics, b, e91-e102.

[4] Stenmark, K.R., Fagan, K.A. and Frid, M.G. (2006) Hypoxia-induced pulmonary vascular remodeling: Cellular and molecular mechanisms. Circulation Research, 99, 675691.

http://dx.doi.org/10.1161/01.RES.0000243584.45145.3f

[5] Evans, A.M., Hardie, D.G., Peers, C., Wyatt, C.N., Viollet, B., Kumar, P., et al. (2009) Ion channel regulation by AMPK: The route of hypoxia-response coupling in the carotid body and pulmonary artery. Annals of the New York Academy of Sciences, 1177, 89-100. http://dx.doi.org/10.1111/j.1749-6632.2009.05041.x

[6] Horman, S., Morel, N., Vertommen, D., Hussain, N., Neumann, D., Beauloye, C., et al. (2008) AMP-activated protein kinase phosphorylates and desensitizes smooth muscle myosin light chain kinase. The Journal of BioLogical Chemistry, 283, 18505-18512. http://dx.doi.org/10.1074/jbc.M802053200

[7] Hattori, Y., Akimoto, K., Nishikimi, T., Matsuoka, H. and Kasai, K. (2006) Activation of AMP-activated protein kinase enhances angiotensin ii-induced proliferation in cardiac fibroblasts. Hypertension, 47, 265-270. http://dx.doi.org/10.1161/01.HYP.0000198425.21604.aa

[8] Park, H.U., Suy, S., Danner, M., Dailey, V., Zhang, Y., Li, H., et al. (2009) AMP-activated protein kinase promotes human prostate cancer cell growth and survival. Molecular cancer therapeutics, 8, 733-741. http://dx.doi.org/10.1158/1535-7163.MCT-08-0631

[9] Mishra, R., Cool, B.L., Laderoute, K.R., Foretz, N., Viollet, B. and Simonson, M.S. (2008) AMP-activated protein kinase inhibits transforming growth factor-beta-induced Smad3-dependent transcription and myofibroblast transdifferentiation. The Journal of Biological Chemistry, 283, 10461-10469.

http://dx.doi.org/10.1074/jbc.M800902200
[10] Creighton, J., Jian, M., Sayner, S., Alexeyev, M. and Insel, P.A. (2011) Adenosine monophosphate-activated kinase alpha1 promotes endothelial barrier repair. FASEB Journal: Official Publication of the Federation of American Societies for Experimental Biology, 25, 3356-3365.

[11] Evans, A.M., Mustard, K.J.W., Wyatt, C.N., Dipp, M., Kinnear, N.P. and Hardie, D.G. (2006) Does AMP-activated protein kinase couple inhibition of mitochondrial oxidative phosphorylation by hypoxia to pulmonary artery constriction? Advances in experimental medicine and biology, 580, 147-154.

http://dx.doi.org/10.1007/0-387-31311-7 22

[12] Dada, L., Gonzalez, A.R., Urich, D., Soberanes, S., Manghi, T.S., Chiarella, S.E., et al. (2012) Alcohol worsens acute lung injury by inhibiting alveolar sodium transport through the adenosine A1 receptor. PLOS ONE [Electronic Resource], 7, Article ID: e30448. http://dx.doi.org/10.1371/journal.pone.0030448

[13] Gusarova, G.A., Dada, L.A., Kelly, A.M., Brodie, C., Witters, L.A., Chandel N.S. and Sznajder, J.I. (2009) Alpha1-AMP-activated protein kinase regulates hypoxiainduced $\mathrm{Na}, \mathrm{K}-\mathrm{ATPase}$ endocytosis via direct phosphorylation of protein kinase $\mathrm{C}$ zeta. Molecular and cellular biology, 29, 3455-3464. http://dx.doi.org/10.1128/MCB.00054-09

[14] Gusarova, G.A., Trejo, H.E., Dada, L.A., Briva, A., Welch, L.C., Hamanaka, R.B., et al. (2011) Hypoxia leads to $\mathrm{Na}, \mathrm{K}-\mathrm{ATPa} e$ downregulation via $\mathrm{Ca}(2+)$ release-activated $\mathrm{Ca}(2+)$ channels and AMPK activation. Molecular and cellular biology, 31, 3546-3556.

http://dx.doi.org/10.1128/MCB.05114-11

[15] Mungai, P.T., Waypa, G.B., Jairaman, A., Prakriya, M., Dokic, D., Ball, M.K., et al. (2011) Hypoxia triggers AMPK activation through reactive oxygen species-mediated activation of calcium release-activated calcium channels. Molecular and cellular biology, 31, 3531-3545. http://dx.doi.org/10.1128/MCB.05124-11

[16] Vadász, I., Dada, L.A., Briva, A., Trejo, H.E., Welch, L.C., Chen, J., et al. (2008) AMP-activated protein kinase regulates $\mathrm{CO}_{2}$-induced alveolar epithelial dysfunction in rats and human cells by promoting $\mathrm{Na}, \mathrm{K}-\mathrm{ATP}$ ase endocytosis. Journal of Clinical Investigation, 118, 752-762.

[17] Ibe, J.C., Zhou, Q., Chen, T., Tang, H., Yuan, J.X., Raj, J.U., et al. (2013) AMPK is required for pulmonary artery smooth muscle cell survival and the development of hypoxic pulmonary hypertension. American Journal of Respiratory Cell and Molecular Biology, in Press. http://dx.doi.org/10.1165/rcmb.2012-0446OC

[18] Agard, C., Rolli-Derkinderen, M., Dumas-de-La-Roque, E., Rio, M., Sagan, C., Savineau, J.P., et al. (2009) Protective role of the antidiabetic drug metformin against chronic experimental pulmonary hypertension. British journal of Pharmacology, 158, 1285-1294. http://dx.doi.org/10.1111/j.1476-5381.2009.00445.x

[19] Borst, S.E. and Snellen, H.G. (2001) Metformin, but not exercise training, increases insulin responsiveness in skeletal muscle of Sprague-Dawley rats. Life Sciences, 69, 1497-1507.

http://dx.doi.org/10.1016/S0024-3205(01)01225-5 
[20] Hundal, R.S., Krssak, M., Dufour, S., Laurent, D., Lebon, V., Chandramouli, V., et al. (2000) Mechanism by which metformin reduces glucose production in type 2 diabetes. Diabetes, 49, 2063-2069.

http://dx.doi.org/10.2337/diabetes.49.12.2063

[21] McAlister, F.A., Eurich, D.T., Majumdar, S.R. and Johnson, J.A. (2008) The risk of heart failure in patients with type 2 diabetes treated with oral agent monotherapy. European Journal of Heart Failure, 10, 703-708. http://dx.doi.org/10.1016/j.ejheart.2008.05.013

[22] Davis, B.J., Xie, Z., Viollet, B. and Zou, M.H. (2006) Activation of the AMP-activated kinase by antidiabetes drug metformin stimulates nitric oxide synthesis in vivo by promoting the association of heat shock protein 90 and endothelial nitric oxide synthase. Diabetes, 55, 496-505. http://dx.doi.org/10.2337/diabetes.55.02.06.db05-1064

[23] Fagan, K.A., Oka, M., Bauer, N.R., Gebb, S.A., Ivy, D.D., Morris, K.G., et al. (2004) Attenuation of acute hypoxic pulmonary vasoconstriction and hypoxic pulmonary hypertension in mice by inhibition of Rho-kinase. American journal of physiology Lung cellular and molecular physiology, 287, L656-L664. http://dx.doi.org/10.1152/ajplung.00090.2003

[24] Morrow, V.A., Foufelle, F., Connell, J.M.C., Petrie, J.R., Gould, G.W. and Salt, I.P. (2003) Direct activation of AMP-activated protein kinase stimulates nitric-oxide synthesis in human aortic endothelial cells. The Journal of Biological Chemistry, 278, 31629-31639. http://dx.doi.org/10.1074/jbc.M212831200

[25] Creighton, J. (2011) Targeting therapeutic effects: Subcellular location matters. Focus on "Pharmacological AMPkinase activators have compartment-specific effects on cell physiology". American Journal of Physiology Cell Physiology, 301, C1293-C1295. http://dx.doi.org/10.1152/ajpcell.00358.2011

[26] Kodiha, M., Ho-Wo-Cheong, D. and Stochaj, U. (2011) Pharmacological AMP-kinase activators have compartment-specific effects on cell physiology. American JourNal of Physiology Cell Physiology, 301, C1307-C1315. http://dx.doi.org/10.1152/ajpcell.00309.2011

[27] Viollet, B., Horman, S., Leclerc, J., Lantier, L., Foretz, M., Billaud, M., et al. (2010) AMPK inhibition in health and disease. Critical Reviews in Biochemistry and MoLecular Biology, 45, 276-295. http://dx.doi.org/10.3109/10409238.2010.488215

[28] Viollet, B., Athea, Y., Mounier, R., Guigas, B., Zarrinpashneh, E., Horman, S., et al. (2009) AMPK: Lessons from transgenic and knockout animals. Frontiers in BioScience: A Journal and Virtual Library, 14, 19-44.

[29] Chhipa, R.R., Wu, Y., Mohler, J.L. and Ip, C. (2010) Sur- vival advantage of AMPK activation to androgen-independent prostate cancer cells during energy stress. Cellular Signalling, 22, 1554-1561. http://dx.doi.org/10.1016/i.cellsig.2010.05.024

[30] Igata, M., Motoshima, H., Tsuruzoe, K., Kojima, K., Matsumura, T., Kondo, T., et al. (2005) Adenosine monophosphate-activated protein kinase suppresses vascular smooth muscle cell proliferation through the inhibition of cell cycle progression. Circulation Research, 97, 837-844. http://dx.doi.org/10.1161/01.RES.0000185823.73556.06

[31] Nagata, D., Takeda, R., Sata, M., Satonaka, H., Suzuki, E., Nagano, T. and Hirata, Y. (2004) AMP-activated protein kinase inhibits angiotensin II-stimulated vascular smooth muscle cell proliferation. Circulation, 110, 444451. http://dx.doi.org/10.1161/01.CIR.0000136025.96811.76

[32] Vucicevic, L., Misirkic, M., Janjetovic, K., Harhaji-Trajkovic, L., Prica, M., Stevanovic, D., et al. (2009) AMPactivated protein kinase-dependent and independent mechanisms underlying in vitro antiglioma action of compound C. Biochemical Pharmacology, 77, 1684-1693. http://dx.doi.org/10.1016/j.bcp.2009.03.005

[33] Krymskaya, V.P., Snow, J., Cesarone, G., Khavin, I., Goncharov, D.A., Lim, P.N., et al. (2011) mTOR is required for pulmonary arterial vascular smooth muscle cell proliferation under chronic hypoxia. FASEB Journal: Official Publication of the Federation of American Societies for Experimental Biology, 25, 1922-1933.

[34] Evans, A.M. (2006) AMP-activated protein kinase underpins hypoxic pulmonary vasoconstriction and carotid body excitation by hypoxia in mammals. Experimental physiology, 91, 821-827.

http://dx.doi.org/10.1113/expphysiol.2006.033514

[35] Robertson, T.P., Mustard, K.J.W., Lewis, T.H., Clark, J.H., Wyatt, C.N., Blanco, E.A., et al. (2008) AMP-activated protein kinase and hypoxic pulmonary vasoconstriction. European Journal of Pharmacology, 595, 39-43. http://dx.doi.org/10.1016/j.ejphar.2008.07.035

[36] Ben Sahra, I., Laurent, K., Loubat, A., Giorgetti-Peraldi, S., Colosetti, P., Auberger, P., et al. (2008) The antidiabetic drug metformin exerts an antitumoral effect in vitro and in vivo through a decrease of cyclin D1 level. Oncogene, 27, 3576-3586.

http://dx.doi.org/10.1038/sj.onc.1211024

[37] Zhuang, Y. and Miskimins, W.K. (2008) Cell cycle arrest in metformin treated breast cancer cells involves activation of AMPK, downregulation of cyclin D1, and requires p27Kip1 or p21Cip1. Journal of Molecular Signaling, 3, 18. http://dx.doi.org/10.1186/1750-2187-3-18 